\title{
Preparation of Silver Nanoparticles in Ultrasonic Vibration-Induced Nanodroplets of Isopropyl Alcohol in Combination with Ionic Liquids
}

\author{
Ueon Sang Shin, ${ }^{\dagger, *}$ Hyun-Ki Hong, ${ }^{\dagger, *}$ Hae-Won Kim, ${ }^{\dagger, *,}$ and Myoung-Seon Gong ${ }^{\dagger, t, *}$ \\ ${ }^{\dagger}$ Department of Nanobiomedical Science \& WCU Research Center, Dankook University Graduate School, \\ Chungnam 330-714, Korea. E-mail: msgong@dankook.ac.kr \\ *Institute of Tissue Regeneration Engineering (ITREN), Dankook University, Chungnam 330-714, Korea \\ ${ }^{\S}$ Department of Biomaterials Science, School of Dentistry, Dankook University, Chungnam 330-714, Korea \\ Received July 19, 2010, Accepted March 21, 2011
}

\begin{abstract}
Silver nanoparticles $(<10 \mathrm{~nm})$ were prepared in ultrasonic vibration-induced nanodroplets of isopropyl alcohol (IPA) in combination with hydrophobic room temperature ionic liquids (RTILs). The Ag-precursor used were silver (I) complex, $\mathrm{Ag}_{2}(\mathrm{ehac})_{2}(\mathrm{eha})_{2}$ (ehac = 2-ethylhexylammonium carbamate; eha = 2-ethylhexylamine), in IPA, while 1-butyl-3-methylimidazolium-based ionic liquids bearing $\mathrm{SbF}_{6}{ }^{-}, \mathrm{PF}_{6}{ }^{-}$and $\mathrm{NTf}_{2}^{-}$as counter anions were used as RTILs. During sonication for 10-90 min at room temperature, uniform silver nanoparticles with mean sizes of 2 to $8 \mathrm{~nm}$ were rapidly synthesized. Transmission electron micrographs also confirmed that silver nanoparticles have a spherical shape and diverse sizes depending on the reaction time (10-90 $\mathrm{min})$.
\end{abstract}

Key Words : Silver nanoparticles, Ionic liquids, Nanodroplets

\section{Introduction}

Silver nanoparticles (Ag-NPs) have received considerable attention in a wide variety of areas due to their unique antimicrobial properties, ${ }^{1-3}$ especially for use in medicinerelated fields such as wound dressings, contraceptive devices, surgical instruments and bone prostheses. ${ }^{4,5}$ For this purpose, the size of nanoparticles needs to be carefully considered. ${ }^{6,7}$ Commonly, the size of the particles tends to influence the toxicity of the cells and tissues, and the smaller particles are considered to be less dangerous. ${ }^{8,9}$ Accordingly, adjusting the size of $\mathrm{Ag}$ particles within the nano-scale $(<100 \mathrm{~nm})$ has become important in terms of size-related cytotoxicity.

Room temperature ionic liquids (RTILs) have many fascinating properties including tunable polarity and hydrophobicity. Therefore, they have been used as green solvents for liquid-liquid separations, extractions and recycling in homogeneous catalysis. Moreover it is well known that imidazolium rings contain the acidic proton of $\mathrm{C} 2-\mathrm{H}\left(\mathrm{p} K_{\mathrm{a}} \cong\right.$ 24 ), which can closely interact with negative-charged species such as the anions of solvent or solute molecules via hydrogen bonding. ${ }^{10-13}$ In the presence of base, $\mathrm{C} 2-\mathrm{H}$ can be easily deprotonated, resulting in $N$-heterocyclic carbine formation, which can stabilize transition-metal nanocolloids. ${ }^{14-16}$

Herein, we report a new method for the preparation of size- and shape-controlled Ag-NPs through the use of hydrophobic RTILs in a biphasic system with isopropyl alcohol (Fig. 1). A series of hydrophobic RTILs such as 1butyl-3-methylimidazolium-based ionic liquids bearing $\mathrm{SbF}_{6}^{-}$, $\mathrm{PF}_{6}{ }^{-}$and $\mathrm{NTf}_{2}{ }^{-}$as counter anions and a silver carbamate complex 1, $\mathrm{Ag}_{2}(\mathrm{ehac})_{2}(\mathrm{eha})_{2}(\mathrm{ehac}=2$-ethylhexylammonium carbamate; eha = 2-ethylhexylamine), in isopropyl alcohol (Ag(I)-Ink) as an Ag precursor were employed. The biphasic reaction mixture was emulsified through ultrasonic vibration, leading to the formation of $\mathrm{Ag}(\mathrm{I})$-Ink nanodroplets surrounded by RTILs and the reductive change of silver ions to silver metals within the nanodroplets. This method of preparing metallic nanoparticles will effectively enable the control of the particle size at the nanometer scale as well as the uniformity of the particle size. Moreover, the use of reductants such as metal hydrides and $\mathrm{H}_{2}$ gas was not necessary in the system described here.
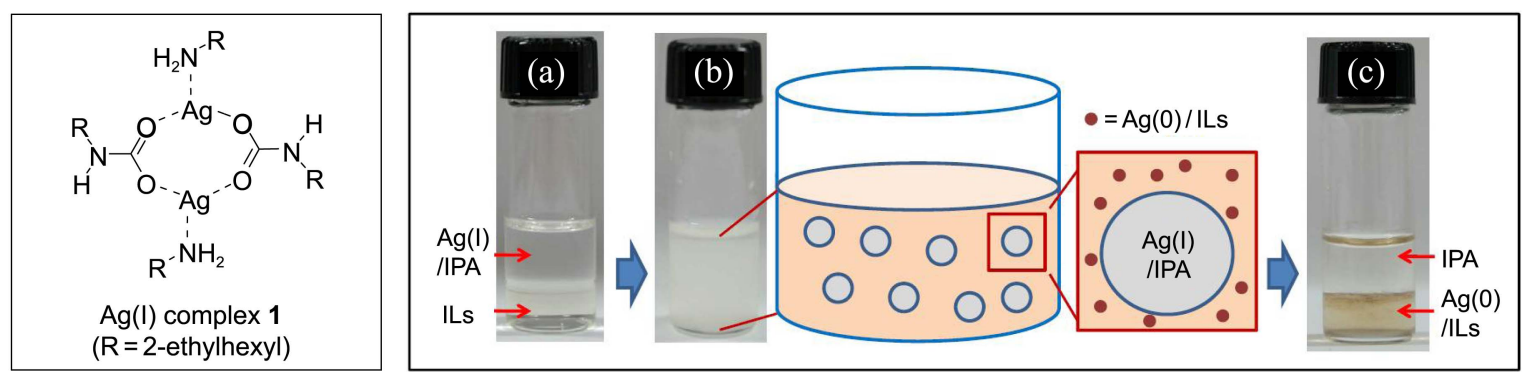

Figure 1. Structure of silver(I) complex 1 and schematic demonstration of the formation of $\operatorname{Ag}(0)$ nanoparticles in IPA nanodroplets; (a) before, (b) during and (c) after ultrasonic vibration. 


\section{Experimental}

Reagents and Analyses. The ILs, [bmim $] \mathrm{X}(\mathrm{bmim}=1$ butyl-3-methylimidazolium cation; $\mathrm{X}=\mathrm{SbF}_{6}, \mathrm{PF}_{6}, \mathrm{NTf}_{2}$, OTf, $\mathrm{BF}_{4}$ and $\mathrm{Cl}$ ), were purchased from C-Tri Co., Ltd., Korea, and used without further purification. [bmim]X $(\mathrm{X}=$ $\mathrm{SbF}_{6}, \mathrm{PF}_{6}, \mathrm{NTf}_{2}$, and $\mathrm{BF}_{4}$ ) was spectrometrically pure, nearly chloride-free $(<5 \mathrm{ppm})$ and had a water content of $<100$ ppm (determined by Karl-Fisher titration). Silver 2ethylhexylcarbamate complex solution (an isopropyl alcohol (IPA) solution of silver(I) complex with 2-ethylhexyl amine and 2-ethylhexylammonium carbamate; $\mathrm{Ag}=10 \mathrm{wt} \%)^{17-25}$ was purchased from InkTec Co., Ltd., Korea and used as a silver-precursor. Other organic solvents were used without distillation. All other chemicals were obtained from commercial sources (Sigma-Aldrich or Merck) and used without further purification. All reactions were conducted at ambient temperature and ultrasonic vibration was used as a mixing tool. Ag-nanoparticles (Ag-NPs) were characterized by TEM and XRD techniques. Nano size and the morphology of the silver nanoparticles were observed using a Philips TECNAI-FE12 transmission electron microscope $(120 \mathrm{kV})$. The particles were dispersed in methanol, after which a drop of the solution was placed on a carbon-coated copper grid and allowed to air-dry. The X-ray diffraction patterns were recorded using a RIGAKU ROTAFLEX RAD-B diffractometer (Rigaku Corp., Japan) using $\mathrm{Cu}$ target $\mathrm{Cu} \mathrm{K} 1$ radiation with a tube voltage of $40 \mathrm{KV}$ and $60 \mathrm{~mA}$ in the range of $5-60^{\circ}$. Isolated organic compounds were characterized by fast-atom bombardment mass spectroscopy (FAB-MS) (JMS-700, Jeol, Japan).

Synthesis of Silver Nanoparticles in Ionic Liquids. Briefly, $1 \mathrm{~g}$ of an ionic liquid was added to a vial followed by $0.1 \mathrm{~g}$ of silver 2-ethylhexylcarbamate complex solution. The solution was then emulsified by subjection to ultrasonic vibration for 10,30 or $90 \mathrm{~min}$. A brown color slowly appeared in ionic liquid phase, indicating the formation of silver (0) nanoparticles. The above solution was then poured into methylene chloride, and the Ag-NPs precipitated onto the bottom of the flask after several hours of standing. Next, the NPs were separated through decantation of the supernatant, after which they were washed with ethanol.

\section{Results and Discussion}

As stated above, we employed a series of hydrophobic RTILs [bmim] X (bmim = 1-butyl-3-methylimidazolium cation; $\mathrm{X}=\mathrm{SbF}_{6}, \mathrm{PF}_{6}$ and $\left.\left.\mathrm{NTf}_{2}\right)\right]$ as a solvent in which IPA solution containing 1 could be easily emulsified to form nanodroplets by sonication. Within a few minutes, $\operatorname{Ag}(\mathrm{I})$ ions confined in the IPA nanodroplets were smoothly transformed to $\operatorname{Ag}(0)$ nanoparticles, which produced a brown color. $\operatorname{Ag}(0)$ nanoparticles formed in IPA nanodroplets rapidly moved into the ionic liquid phase which could effectively stabilize the nanoparticles. ${ }^{14}$ Photographs in Figure 1 clearly show the phase separation before and after sonication and the formation of emulsion during sonication. Moreover, the

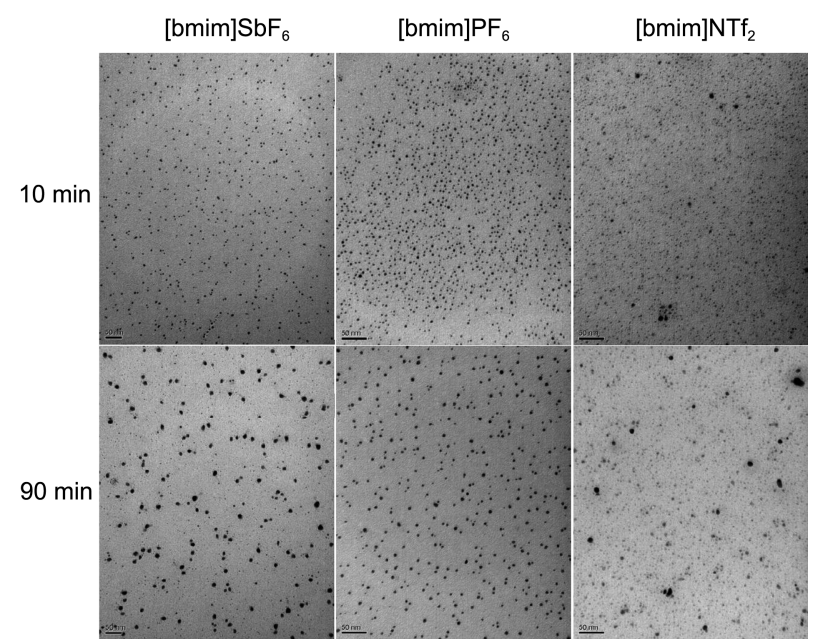

Figure 2. Transmission electron microscope images of Ag-NPs prepared in $[\mathrm{bmim}] \mathrm{SbF}_{6},[\mathrm{bmim}] \mathrm{PF}_{6}$ and $[\mathrm{bmim}] \mathrm{NTf}_{2}$.

movement of Ag-NPs from IPA to the RTIL phase could be easily confirmed by the occurrence of a brown color.

TEM studies of Ag-NPs were conducted to evaluate the shape and size of the particles formed in the presence of [bmim]X $\left(\mathrm{X}=\mathrm{SbF}_{6}, \mathrm{PF}_{6}\right.$ and $\left.\mathrm{NTf}_{2}\right)$. As shown in Figure 2, in the presence of $[\mathrm{bmim}] \mathrm{SbF}_{6}$ and $\left[\mathrm{bmim} \mathrm{PF}_{6}\right.$, generally regular and spherical nanoparticles were formed with a mean size of about $2-8 \mathrm{~nm}$. The particle size could be easily increased by up to $20 \mathrm{~nm}$ in diameter by varying the reaction time from 10 to $90 \mathrm{~min}$. Ag-NPs prepared using [bmim] $\mathrm{NTf}_{2}$ were also spherical, but the size was irregular, which was likely because the hydrophobicity of [bmim $] \mathrm{NTf}_{2}$ was lower than that of the others. Figure 3 representatively shows the particle size distribution calculated based on several TEM images of $\mathrm{Ag}(0)-\mathrm{NPs}$ prepared for 10 and $90 \mathrm{~min}$ in [bmim $] \mathrm{SbF}_{6}$.

To collect Ag-NPs and to see their powder X-ray diffraction pattern, the brown-colored ionic liquid phase prepared through ultrasonic vibration for $90 \mathrm{~min}$ in [bmim] $\mathrm{SbF}_{6}$ was poured into dichloromethane, resulting in a yield of $89 \%$. The powder X-ray diffraction pattern of the nanoparticles showed peaks at 38.8 and $44.4^{\circ}$, conforming the presence of $\operatorname{Ag}(0)$ in the sample (Fig. 3). The peak at $38.8^{\circ}$ with $100 \%$ relative intensity peak counts which confirm $\operatorname{Ag}(0)$, which is same as in the JCPDS cards.

To determine the mechanism of the formation of $\operatorname{Ag}(0)$ NPs, the role of the hydrophobicity of RTILs used should be considered because the phase separation with the hydrophilic IPA phase might be important for effective breaking of the hydrophilic phase into nanometer-sized droplets by ultrasonic vibration. When hydrophilic RTILs such as [bmim]OTf, $[\mathrm{bmim}] \mathrm{BF}_{4}$ and $[\mathrm{bmim}] \mathrm{Cl}$ were employed, no phase separation was observed because of the good miscibility of the ionic liquids with the IPA solution, which resulted in no formation of nanoparticles even after sonication for $3 \mathrm{~h}$.

In addition, the acidity of $\mathrm{C} 2-\mathrm{H}$ of the imidazolium-based ionic liquids ([bmim]X) may be responsible for the reduction of $\operatorname{Ag}(\mathrm{I})$ ions. As proposed in Figure 4, the imidazolium 
(a)

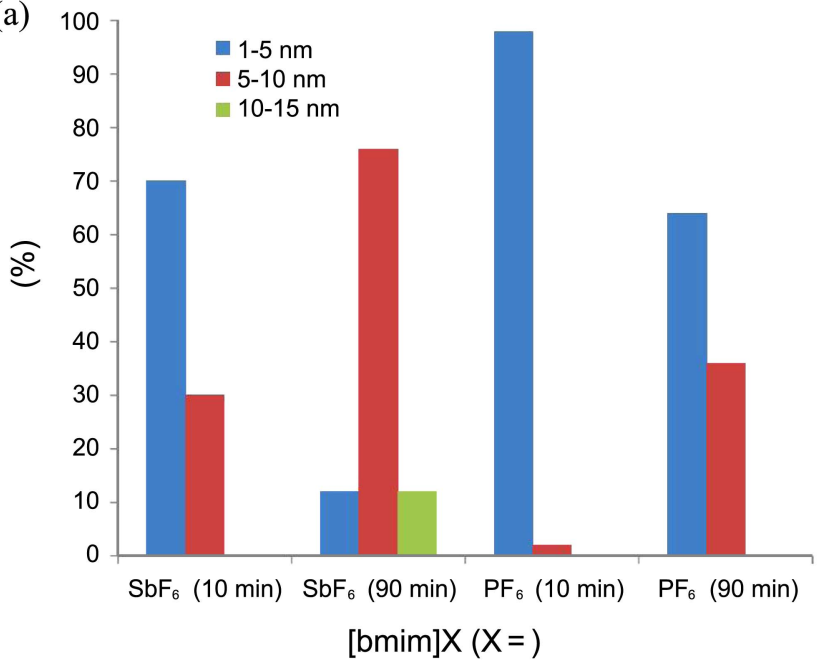

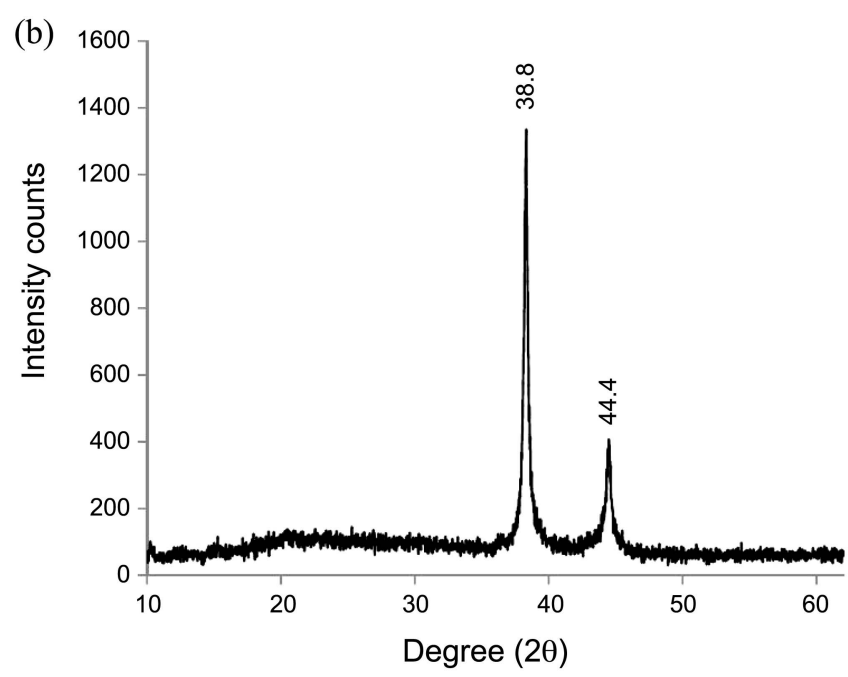

Figure 3. (a) Size distribution (determined by calculation based on several TEM images) of $\mathrm{Ag}(0)-\mathrm{NPs}$ prepared in [bmim] $\mathrm{SbF}_{6}$ and $[\mathrm{bmim}] \mathrm{PF}_{6}$ and $(\mathrm{b})$ powder X-ray diffraction pattern of $\mathrm{Ag}(0)-\mathrm{NPs}$ prepared in $[\mathrm{bmim}] \mathrm{SbF}_{6}$.

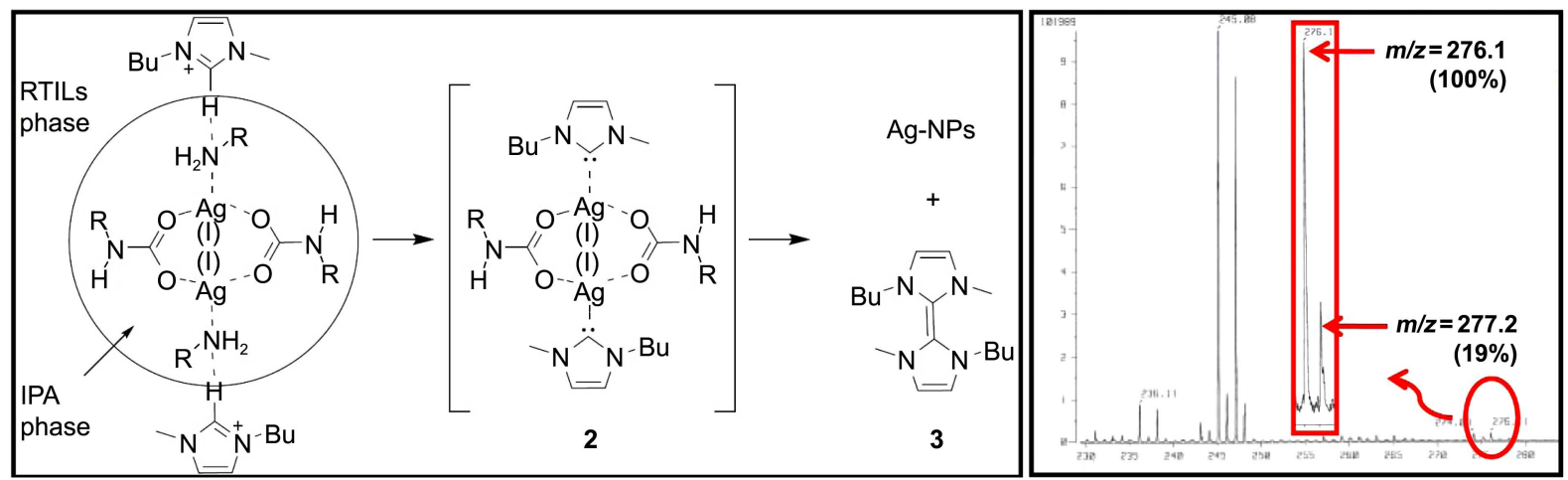

Figure 4. Proposed mechanism for the reduction of $\mathrm{Ag}(\mathrm{I})$ complex (1) to $\mathrm{Ag}(0)$-NPs promoted by imidazolium ionic liquids (left) and FAB mass spectrum of the reaction mixture (right).

cations might effectively enclose the hydrophilic IPA-nanodroplets through hydrogen bonding between the $\mathrm{C} 2-\mathrm{H}$ and IPA phase similar to a nanomicelle. Next, the imidazolium protons could be deprotonated by the amine molecules, which are coordinated with the $\mathrm{Ag}(\mathrm{I})$ ion, to produce $\mathrm{NHCs}$ ( $N$-heterocyclic carbenes). ${ }^{11,15}$ As stated above, the acidity scale of $\mathrm{C} 2-\mathrm{H}$ is largely dependent on the degree of hydrogen bonding between the C2-proton and anion [X]; therefore, the acidity would likely affect the reaction rate. ${ }^{15}$ For example, a less basic anion such as $\mathrm{SbF}_{6}^{-}$is weakly coordinated with the $\mathrm{C} 2$-proton of the imidazolium cation via hydrogen bonding, which leads to a stronger acidity of the C2-proton and a more likely possibility of deprotonation by amines. The NHCs produced could temporally form complex 2 with $\operatorname{Ag}(\mathrm{I})$ ions as an intermediate and then lose their electrons to $\operatorname{Ag}(\mathrm{I})$ ions, affording $\operatorname{Ag}(0)$ and a $N$-heterocyclic dimer 3. ${ }^{11,15}$ Fortunately, we could confirm the presence of $\mathbf{3}$ in RTILs phase after characterization by FAB mass (Fig. 4). FAB mass spectrum shows a prominent peak at $m / z=276$ which corresponds to the compound $3, \mathrm{C}_{16} \mathrm{H}_{28} \mathrm{~N}_{4}$. Finally, $\mathrm{Ag}(0)-\mathrm{NPs}$ formed could be rapidly transferred into the
RTIL phase, where they would be stabilized by surrounding imidazolium cations. ${ }^{14}$

\section{Conclusion}

Here, the application of room temperature ionic liquids (RTILs) as solvents for the formation of nanodroplets of isopropyl alcohol (IPA) containing a silver 2-ethylhexylcarbamate complex, leading to the formation of Ag-nanoparticles is reported. The RTILs used in this study were 1butyl-3-methylimidazolium-based ionic liquids bearing $\mathrm{SbF}_{6}^{-}$, $\mathrm{PF}_{6}{ }^{-}$and $\mathrm{NTf}_{2}{ }^{-}$as counter anions. During sonication for $10-$ $90 \mathrm{~min}$ at room temperature, uniform silver nanoparticles $(<10 \mathrm{~nm})$ were rapidly synthesized without using external and typical reductants including various hydrides and $\mathrm{H}_{2}$ gas. Transmission electron micrographs confirmed that silver nanoparticles are regular spheres with mean sizes in the range of 2-8 $\mathrm{nm}$. The characterization of the as-prepared nanoparticles was also conducted using transmission electron micrographs and the X-ray diffraction method. 
Acknowledgments. This work was supported by Priority Research Centers Program (grant\#: 2009-0093829) and WCU (World Class University) program (grant\#: R31-10069) through the National Research Foundation (NRF) funded by the Ministry of Education, Science and Technology. Authors greatly thank the support of IBST of Dankook University.

\section{References}

1. Singh, M.; Sinha, K.; Mandal, R. K. Mater. Lett. 2009, 63, 425.

2. Yon, J. N.; Jamie, R. L. Sci. Total. Enviro. 2008, 1-3, 396.

3. Jeon, H. J.; Yi, S. C.; Oh, S. G. Biomaterials 2003, 24, 4921.

4. Cohen, M. S.; Stern, J. M.; Vanni, A. J.; Kelley, R. S.; Baumgart,. E.; Field, D.; Libertino, J. A.; Summerhayes, I. C. Surg. Infect. (Larchmt) 2007, 8, 397.

5. Fu, J.; Ji, J.; Fan, D.; Shen, J.; Biomed, J. Mater. Res. A 2006, 79, 665.

6. Miura, N.; Shinohara, Y. Biochem. Biophys. Res. Commun. 2009, 390, 733 .

7. Lewinski, N.; Colvin, V.; Drezek, R. Small 2008, 4, 26.
8. Gopinath, P.; Gogoi, S. K.; Sanpui, P.; Paul, A.; Chattopadhyay, A.; Ghosh, S. S. Colloid. Surf. B Biointerf. 2010, 77, 240.

9. Wang, J.; Rahman, M. F.; Duhart, H. M.; Newport, G. D.; Patterson, T. A.; Murdock, R. C.; Hussain, S. M.; Schlager, J. J.; Ali, S. F. NeuroToxicology 2009, 30, 926.

10. Wang, R.; Yuan, L.; Macartney, D. H. Chem. Commun. 2006, 2908.

11. Ott, L. S.; Cline, M. L.; Deetlefs, M.; Seddon, K. R.; Finke, R. G. J. Am. Chem. Soc. 2005, 127, 5758.

12. Herrmann, W. A.; Kocher, C. Angew. Chem. Int. Ed. 1997, 36, 2162.

13. Aggarwal, A.; Lancaster, N. L.; Sethi, A. R.; Welton, T. Green Chem. 2002, 4, 517.

14. Dupont, J.; Fonseca, G. S.; Umpierre, A. P.; Fichtner, P. F. P.; Teixeira, S. R. J. Am. Chem. Soc. 2002, 124, 4228.

15. Choi, D. S.; Kim, D. H.; Shin U. S; Deshmukh, R. R.; Lee, S. G.; Song, C. E. Chem. Commun. 2007, 3467.

16. Kim, Y. J.; Streitwieser, A. J. Am. Chem. Soc. 2002, 124, 5757.

17. The silver 2-ethylhexylcarbamate complex solution (silver content, $10 \%$ ) was supplied from Inktec Co. Ltd. (Korea). Alessio, R.; Dell'Amico, D. B.; Calderazzo, F.; Englert, U.; Guarini, A.; Labella, L.; Strasser, P. Helv. Chim. Acta 1998, 81, 219.

18. Jeon, Y.-M.; Gong, M.-S. Macromol. Res. 2009, 17, 2. 